\title{
Energy metabolism in relation to body composition and gender in adolescents
}

\author{
E G A H van Mil, K R Westerterp, A D M Kester, W H M Saris
}

\begin{abstract}
Objective-To study the effect of body composition on average daily metabolic rate (ADMR) and basal metabolic rate (BMR) in adolescence, and to examine current BMR prediction equations.

Study-Dutch adolescents were pooled with previously reported American and British subjects ( $\mathrm{n}=90$ overall). BMR and ADMR were analysed by multiple regression.

Results-Fat-free mass, BMR, and ADMR were higher in the obese than in the non-obese group (mean (SD): 53.2 (10.7) $\mathrm{kg}, 8.35$ (1.57) MJ/d, and 13.64 (2.78) MJ/d, compared with 41.0 (8.1) $\mathrm{kg}, 6.42$ (0.94) $\mathrm{MJ} / \mathrm{d}$, and 11.16 (2.21) $\mathrm{MJ} / \mathrm{d}$, respectively). BMR remained higher when adjusted for fat-free mass, age, and sex. ADMR adjusted for BMR was similar in the two groups. WHO equations overestimated BMR in obese boys and underestimated BMR in non-obese boys. Conclusions-BMR, but not activity, is increased in obese adolescents and in male adolescents. The WHO BMR equations for adults are recommended for obese adolescents.

(Arch Dis Child 2001;85:73-78)
\end{abstract}

Departments of

Human Biology and

Paediatrics, Nutrition

Toxicology and

Environment Research

Institute Maastricht,

Maastricht University,

PO Box 616,

Maastricht $6200 \mathrm{MD}$,

Netherlands

E G A H Van Mil

K R Westerterp

W H M Saris

Department of Methodology and Statistics, Nutrition Toxicology and

Environment Research Institute Maastricht A D M Kester

Correspondence to:

Dr van Mil

email:

g.vanmil@hb.unimaas.nl

Accepted 9 January 2001

The prevalence of overweight and obesity in children and adolescents is rapidly increasing in Western societies. ${ }^{1-4}$ Obesity during adolescence is associated with raised blood pressure and lipid profiles, which increase the risk of obesity related disease and mortality. ${ }^{5-8}$ Awareness is growing that the long term cardiovascular health of the next generation of adults is an issue of concern. ${ }^{9-11}$ Moreover, the obese adolescent has the highest risk of becoming an obese adult, ${ }^{12}$ regardless of parental obesity. ${ }^{13}$ Because obesity in adult life remains difficult to treat, ${ }^{14}$ the adolescent age group is of increasing interest as a target for obesity treatment. ${ }^{15}$ Knowledge of energy metabolism in adolescents is thus of vital importance for future obesity interventions.

Obesity is characterised by excess adipose tissue. The extra weight that results consists not only of fat mass but also of fat-free mass.
Generally, energy expenditure is increased not only because the increased fat-free mass results in a rise in basal metabolic rate (BMR), but also because of the higher energy cost of weight bearing activities. ${ }^{16}$ During adolescence, however, growth spurts and biological maturation may have additional effects on body composition and energy expenditure. ${ }^{17} 18$ Because of these potential confounding factors, several studies measuring basal metabolism in obese adolescents ${ }^{19-25}$ have tested the validity of existing BMR prediction equations, ${ }^{26}$ often generating new equations..$^{25}$ Only one study has addressed the effect of obesity on BMR as well as on total energy expenditure - or average daily metabolic rate (ADMR) - in this age group. ${ }^{27}$

Our aim in the study was to examine the relation between ADMR, BMR, and body composition in obese and non-obese male and female adolescents. Because of economic constraints, our objectives were achieved by using results from our own study centre pooled with previously published data. The specific objectives were first, to examine the nature of the relation between ADMR, BMR, and fat-free mass in adolescents, using recommended laboratory techniques; second, to determine the effects of fat mass and sex on ADMR and BMR in this age group; and third, to assess whether existing $\mathrm{FAO} / \mathrm{WHO} / \mathrm{UNU}$ equations can be used to predict BMR in lean and obese adolescents, defining obesity according to current recommendations. ${ }^{28}$

\section{Methods}

A Medline and cross reference search was performed for existing datasets on ADMR and BMR in adolescents. Inclusion criteria were:

- individually reported measures of fat-free mass, BMR, and ADMR from peer reviewed journal articles;

- subjects to be between 12 and 18 years of age and with no disease state other than obesity;

- total body water and ADMR had to be measured by doubly labelled water (free living) and BMR by ventilated hood. Fatfree mass had to be calculated by total body water.

The results were extracted from each report and pooled. For each individual, information about centre localisation, sex, body weight, 
Table 1 Characteristics of obese and non-obese adolescent subjects

\begin{tabular}{lllllll}
\hline Variable & NL-O & US-O & Obese (all) & UK- & US- $N$ & Non-obese (all) \\
\hline Sex (F:M) & $11: 13$ & $12: 15$ & $23: 28$ & $8: 8$ & $10: 13$ & $18: 21$ \\
Age (years) & $13.9(1.3)^{\star}$ & $15.0(1.9)$ & $14.5(1.7)$ & $13.5(1.6)$ & $14.3(1.3)$ & $14.0(1.5)$ \\
Height $(\mathrm{cm})$ & $163.4(6.4)$ & $166.8(7.9)$ & $165.2(7.4)$ & $158.6(10.9)$ & $164.2(8.6)$ & $161.9(9.9)$ \\
Weight $(\mathrm{kg})$ & $85.0(16.2)^{\star \star}$ & $101.4(23.2)$ & $93.7(21.7) \dagger$ & $47.7(8.3) \ddagger$ & $55.3(9.5)$ & $52.2(9.7)$ \\
BMI $\left(\mathrm{kg} / \mathrm{m}^{2}\right)$ & $31.7(4.9)^{\star}$ & $36.3(7.7)$ & $34.1(6.9) \dagger$ & $19.0(2.9)$ & $20.5(2.8)$ & $19.9(2.9)$ \\
\hline
\end{tabular}

Values are mean $(\mathrm{SD})$ or $\mathrm{n}$.

${ }^{\star} \mathrm{p}<0.05,{ }^{\star \star} \mathrm{p}<0.01 v$ US-O.

tp $<0.001 v$ non-obese.

$\neq \mathrm{p}<0.05$ v US-N.

NL-O, obese group from the Maastricht area; UK-N, non-obese group from the Belfast area; US-N, non-obese group from the Boston area; US-O, obese group from the Boston area.

height, fat-free mass, fat mass, BMR, and ADMR was extracted into the database. Subject characteristics are shown in table 1.

SUBJECTS AND PROTOCOL OF STUDY CENTRE MAASTRICHT

Twenty four obese subjects (age 12.0 to 17.4 years) with a body mass index (BMI) and triceps skinfold thickness greater than or equal to the 97 th centile for age and $\operatorname{sex}^{29}$ were recruited from the regional public health department and paediatric outpatient clinic of the university hospital Maastricht. Subjects with endocrine causes or other secondary causes of obesity were excluded. Before the start of the study the parents gave written informed consent, confirmed by the oral approval of the child. The study was approved by the medical ethics committee of Maastricht University.

Height, weight, and BMR measurements have been described in detail previously, ${ }^{30} 31$ and total body water and ADMR were measured according to the Maastricht protocol for the measurement of body composition and energy expenditure with labelled water. ${ }^{32}$ In summary, the subject received an oral dose of ${ }^{2} \mathrm{H}_{2} \mathrm{O}$ and $\mathrm{H}_{2}{ }^{18} \mathrm{O}$ as the last drink before bedtime. A urine sample was taken 10 hours after this dose from the second voiding the next morning (day 1). Isotope abundance in the urine was determined using an isotope ratio mass spectrometer (Aqua Sira, VG Isogas, Micromass, Manchester, UK). Total body water was calculated as the ${ }^{2} \mathrm{H}$ dilution space divided by 1.04 , correcting for exchange of the ${ }^{2} \mathrm{H}$ label with non-aqueous $\mathrm{H}$ of body solids. ${ }^{33}$ Fat-free mass was assessed on the assumption that the fat-free mass contains all the body water, using a hydration factor of 0.73 . Isotope disappearance rates in the urine from the samples taken on days 1,8 , and 14 from the subsequent 14 days were used to calculate carbon dioxide production. Carbon dioxide production was converted to average daily metabolic rate (total energy expenditure), with a respiratory exchange ratio equal to the food quotient that was derived from a one week food diary.

Table 2 FAO/WHO/UNU calculations of BMR

\begin{tabular}{llll}
\hline WHO-1 & \multirow{2}{*}{$10-18$ years } & Male & $0.0732^{\star}$ weight $+2.72(\mathrm{MJ} / \mathrm{d})$ \\
& & Female & $0.0510^{\star}$ weight $+3.12(\mathrm{MJ} / \mathrm{d})$ \\
WHO-2 & \multirow{2}{*}{$10-18$ years } & Male & $69.4^{\star}$ weight $+322.2^{\star}$ height $+2392(\mathrm{~kJ} / \mathrm{d})$ \\
& & Female & $30.9^{\star}$ weight $+2016.6^{\star}$ height $+907(\mathrm{~kJ} / \mathrm{d})$ \\
WHO-1a & \multirow{2}{*}{$18-30$ years } & Male & $0.0640^{\star}$ weight $+2.84(\mathrm{MJ} / \mathrm{d})$ \\
& & Female & $0.0615^{\star}$ weight $+2.08(\mathrm{MJ} / \mathrm{d})$ \\
WHO-2a & \multirow{2}{*}{$18-30$ years } & Male & $64.4^{\star}$ weight $-113.0 \star$ height $+3000(\mathrm{~kJ} / \mathrm{d})$ \\
& & Female & $55.6^{\star}$ weight $+1397.4{ }^{\star}$ height $+146(\mathrm{~kJ} / \mathrm{d})$ \\
\hline
\end{tabular}

On day 1, BMR measurement was started after the subject had been lying supine for 10 minutes. Oxygen consumption and carbon dioxide production were measured over $40-50$ minutes - using a computerised open circuit ventilated hood system - while the subject was watching television. Gas analyses were performed using a paramagnetic oxygen analyser (Servomex, Crowborough, UK) and an infrared carbon dioxide analyser (Uras 3G, Hartmann and Braun, Frankfurt, Germany). BMR was calculated according to $\mathrm{Weir}^{34}$ over the 14 minute interval with the lowest standard deviation.

BMR PREDICTION EQUATIONS

BMR was calculated according to the prediction equations of the Food and Agriculture Organisation (FAO), the World Health Organisation (WHO), and United Nations University $(\mathrm{UNU})^{18}$ on the basis of weight (WHO-1), and weight in combination with height (WHO-2) for ages 10-18 years, as well as for ages 18-30 years (WHO-1a and WHO-2a, respectively) (table 2).

\section{STATISTICAL ANALYSIS}

All subjects included in the study (from the Maastricht centre as well as from the other centres that met the inclusion criteria) were pooled. According to the current recommendations, ${ }^{28}$ the common criterion for obesity was a BMI above the 95th centile for age and sex. Differences in independent variables between the obese and non-obese groups and between the centres - as well as sex differences within the pooled groups-were analysed by the two sample $t$ test. Differences in the mean of the measured and predicted BMR in male and female subjects were determined with a paired $t$ test as a measure of accuracy. To measure the precision of the BMR predictions, the mean absolute error for each subgroup was calculated.

Second, a multiple linear regression model with BMR as the dependent variable and fat-free mass, age, and sex as independent variables was used to analyse the difference in BMR between the obese and non-obese adolescents, defined by the binary variable group. The difference in regression slope of the influence of fat-free mass on BMR was tested using interaction variables of group and fat-free mass and group and sex, after correction for the variables in the equation. The difference between groups, corrected for these independent variables, was then estimated and tested for significance using linear regression, assuming 
Table 3 Energy expenditure and body composition of obese and non-obese adolescents

\begin{tabular}{lllllll}
\hline Variable & NL-O & US-O & Obese (all) & UK- $N$ & US-N & Non-obese (all) \\
\hline FFM (kg) & $49.0(8.5)^{\star \star}$ & $56.8(11.4)$ & $53.2(10.7) \dagger+\dagger$ & $36.6(6.4) \neq \ddagger$ & $44.1(7.8)$ & $41.0(8.1)$ \\
FM (kg) & $35.9(9.6)^{\star}$ & $44.6(15.1)$ & $40.5(13.4) \dagger+\dagger$ & $11.0(5.4)$ & $11.2(5.0)$ & $11.1(5.1)$ \\
\%FM (\%) & $42.0(4.9)$ & $43.1(6.8)$ & $42.6(6.0) \dagger+\dagger$ & $22.8(7.9)$ & $20.0(7.2)$ & $21.2(7.6)$ \\
BMR (MJ/d) & $7.81(1.32)^{\star}$ & $8.83(1.65)$ & $8.35(1.57) \dagger+\dagger$ & $6.02(0.86) \ddagger$ & $6.71(0.91)$ & $6.42(0.94)$ \\
ADMR (MJ/d) & $12.14(2.19)^{\star \star \star}$ & $14.98(2.58)$ & $13.64(2.78) \dagger+\dagger$ & $10.28(1.38) \ddagger$ & $11.77(2.49)$ & $11.16(2.21)$ \\
PAL & $1.56(0.18)^{\star \star}$ & $1.71(0.18)$ & $1.64(0.19) \dagger$ & $1.72(0.18)$ & $1.75(0.24)$ & $1.73(0.21)$
\end{tabular}

Values are mean (SD)

${ }^{\star} \mathrm{p}<0.05,{ }^{\star \star} \mathrm{p}<0.01,{ }^{\star \star \star} \mathrm{p}<0.001 v$ US-O.

tp $<0.05,+t+\mathrm{p}<0.001 v$ non-obese.

$\neq \mathrm{p}<0.05, \pm \neq \mathrm{p}<0.01 v$ US-N.

NL-O, obese group from the Maastricht area; UK-N, non-obese group from the Belfast area; US-N, non-obese group from the Boston area; US-O, obese group from the Boston area; PAL, physical activity level (ADMR/BMR).

equal slopes. The same procedure was done with $\mathrm{ADMR}$ as the dependent variable, again with fat-free mass, age, and sex as independent variables, and obesity as the grouping variable. This analysis was repeated with BMR instead of fat-free mass as covariate.

Finally, to detect differences between centres, these procedures were repeated within the complete study sample with the study centre as the grouping variable.

The significance level was chosen as $5 \%$. Data are expressed as mean (SD). SPSS release 6.1 for Macintosh (SPSS Inc, Chicago, Illinois, USA) was used as the statistical package.

\section{Results}

Of the five BMR and ADMR studies in adolescents ${ }^{27}{ }^{35-38}$ that were found in published reports, two met the inclusion criteria: that of Bandini et $a l,{ }^{27}$ who measured obese as well as non-obese adolescents in the Boston region (Mssachusetts, USA), and that of Livingstone et $a l,{ }^{36}$ who measured children and adolescents of age $7,9,12$, and 15 years in the Belfast area (Northern Ireland, United Kingdom). For the present study, based on subjects between 12 and 18 years of age, only the adolescent groups (12 and 15 years) in Livingstone's report are included. All the obese American and Dutch subjects met the common obesity criterion of BMI > 95th centile for age and sex, whereas the other American and British subjects did not. Thus there were two groups of obese adolescents (American and Dutch: US-O and NL-O) and two groups of non-obese adolescents (American and British: US-N and UK-N). When combined, these formed a pooled group of 90 subjects. There were no statistically significant differences between the groups for sex and height. However, in the obese group as well as in the non-obese group the Americans were heavier than their European counterparts. The US-O group was also older than the NL-O group (table 1). Fat-free mass, fat mass, $\%$ fat mass, BMR, ADMR, and physical activity level (ADMR/BMR) were all higher in the obese adolescents. Within the obese group, fat-free mass and fat mass were higher in the US-O group than in the NL-O group, while \% fat mass was similar. BMR, ADMR, and physical activity level were also higher in US-O. Within the non-obese group, there was a higher fat-free mass, BMR, and ADMR in the US-N group than in the British adolescents (table 3 ).

There were no differences between male and female subjects in age, height, weight, or BMI within the obese and non-obese groups (not shown). In addition, fat-free mass was similar, whereas \% fat mass was lower in male than in female subjects, but only in the non-obese group (mean (SD): 17.1 (5.4)\% v 25.9 (7.0)\% $(\mathrm{p}<0.0001))$. BMR was higher in male than in female subjects in both the obese and nonobese groups (8.90 (1.58) v 7.69 (1.31) MJ/d $(\mathrm{p}<0.01)$, and $6.95(0.84) v 5.81(0.64) \mathrm{MJ} / \mathrm{d}$ $(\mathrm{p}<0.001)$, respectively). A significant difference between male and female subjects was also found in ADMR for both the obese and the non-obese groups (14.45 (2.69) $v 12.67$ (2.63) $\mathrm{MJ} / \mathrm{d}(\mathrm{p}<0.05)$, and 12.17 (2.02) $v$ 9.98 (1.83) MJ/d ( $1<0.01)$, respectively). There were no sex differences in physical activity level.

BMR adjusted for fat-free mass resulted in a higher BMR in the obese group than in the non-obese group, even when also adjusted for age and sex. For the complete study sample,

Table $4 \mathrm{FAO} / \mathrm{WHO} / \mathrm{UNU}$ prediction equations for basal metabolic rate (BMR) of male and female subjects in the obese and non-obese groups

\begin{tabular}{|c|c|c|c|c|c|c|}
\hline Group & $\operatorname{Sex}$ & $B M R(M f / d)$ & WHO-1 (MF/d) & $W H O-2(M F / d)$ & WHO-1a $(M \mathcal{H} / d)$ & WHO-2a (MF/d) \\
\hline \multirow[t]{3}{*}{ Obese } & Male & $8.90(1.58)$ & $9.62(1.63)^{\star \star \star}$ & $9.46(1.56)^{\star \star}$ & $8.86(1.42)$ & $8.87(1.43)$ \\
\hline & Female & $7.69(1.31)$ & $7.88(1.10)$ & $7.10(0.72) \int S$ & $7.81(1.32)$ & $6.73(1.19) \rrbracket$ \\
\hline & Total & $8.35(1.57)$ & $8.84(1.65) \mathrm{t \dagger}+$ & $8.40(1.72)$ & $8.39(1.46)$ & 7.91 (1.70)†† \\
\hline \multirow[t]{3}{*}{ Non-obese } & Male & $6.95(0.84)$ & $6.55(0.75)$ 㧊 & $6.54(0.74) \neq \ddagger$ & 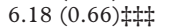 & $6.18(0.65)$ 柿 \\
\hline & Female & $5.81(0.64)$ & $5.79(0.48)$ & $5.74(0.38)$ & $5.29(0.58) \$ \$$ & $4.45(0.52) \$ \$ \$$ \\
\hline & Total & $6.42(0.94)$ & $6.19(0.74)$ & $6.17(0.72)$ & $5.77(0.76)$ ตฯ & $5.38(1.05)$ ตा \\
\hline
\end{tabular}

Values are mean $(\mathrm{SD})$.

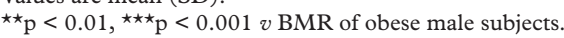

( $\mathrm{p}<0.05$, S $\mathrm{p}<<0.01 v$ BMR of obese female subjects.

$+\dagger \mathrm{p}<0.01,+\dagger+\mathrm{p}<0.001 v$ BMR of obese group.

$\neq \neq \mathrm{p}<0.01, \neq \neq \neq \mathrm{p}<0.001 v$ BMR of non-obese male subjects.

$\$ \$ \mathrm{p}<0.01, \$ \$ \$ \mathrm{p}<0.001 v$ BMR of non-obese female subjects.

$\uparrow \mathrm{p}<0.05, \boldsymbol{\uparrow} \uparrow \uparrow \mathrm{p}<0.001 v \mathrm{BMR}$ of non-obese group.

FAO/WHO/UNU, Food and Agriculture Organisation/World Health Organisation/United Nations University: WHO-1: equations based on weight for age 10-18 years; WHO-2: equations based on weight and height for age 10-18 years; WHO-1a: equations based on weight for age 18-30 years; WHO-2a: equations based on weight and height for age 18-30 years. 


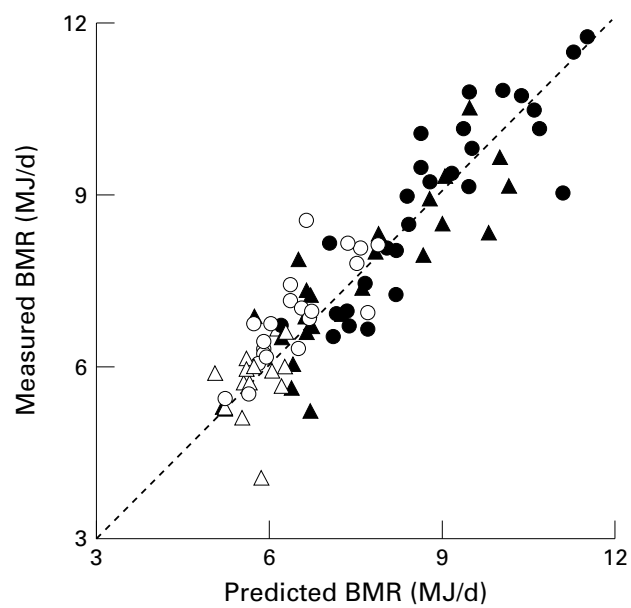

Figure 1 Measured basal metabolic rate (BMR, in $M F / d)$ as a function of predicted $\mathrm{BMR}$ by $\mathrm{FAO} / \mathrm{WHO} / \mathrm{UNU}$ equations (in MF/d). The obese group (filled symbols) is predicted by adult BMR equations based on weight, and the non-obese group (empty symbols) is predicted by adolescent equations based on height and weight. Female subjects are represented by triangles, male subjects by circles. The dotted line represent the line of identity.

fat-free mass accounted for $80 \%$ of the observed variance. Other significant determinants in the prediction of BMR were age and sex.

Both WHO-1 and WHO-2 overestimated the measured $\mathrm{BMR}$ in obese male subjects (mean absolute error $(\mathrm{MAE})=723$ and $562 \mathrm{~kJ}$, respectively); however, they underestimated $\mathrm{BMR}$ in the non-obese male subjects $(\mathrm{MAE}=$ 405 and $412 \mathrm{~kJ}$ ), as demonstrated by the differences in the means shown in table 4 . Conversely, WHO-2 underestimated BMR in obese female subjects $(\mathrm{MAE}=591 \mathrm{~kJ})$, while the BMR of both obese and non-obese females was adequately predicted by WHO-1 $(\mathrm{MAE}=$ 189 and $19 \mathrm{~kJ}$, respectively). WHO-1a and WHO-2a underestimated BMR in non-obese male and female subjects (MAE $=773$ and 778 $\mathrm{kJ}$, and 517 and $136 \mathrm{~kJ}$, respectively); however, the measured BMR in obese male and obese female subjects was best predicted by WHO-1a $(\mathrm{MAE}=33$ and $119 \mathrm{~kJ})$. Thus WHO-2 had the lowest MAE for the non-obese male and female subjects, while WHO-1a had the lowest MAE in the obese male and female subjects. In fig $1, B M R$ is a function of the BMR prediction of the WHO-2 for the non-obese adolescents and WHO-1a for the obese adolescents, as these prediction equations had the smallest MAE in each group.

ADMR adjusted for fat-free mass resulted in equal outcomes for the obese and the nonobese group even when adjusted for age and sex, the latter negatively influencing ADMR. Fat-free mass accounted for $66 \%$ of the observed variance, which could be increased by including age and sex in the equation, adding $5 \%$ to the explained variance. For the complete study sample, BMR accounted for $71 \%$ of the observed variance, while age - as the only other significant predictor for ADMR - increased the explained variance to $72 \%$.

\section{Discussion}

Because there is a scarcity of studies on total energy expenditure in obese as well as nonobese adolescents, our aim in the present study was to combine energy expenditure and body composition data from obese adolescents from the Maastricht region with individual data from the USA (Boston area) ${ }^{27}$ and the United Kingdom (Belfast area) ${ }^{36}$ to determine the effect of obesity and sex on energy metabolism in this age group.

BMR adjusted for fat-free mass was higher in the obese group. Although sex and age, as known predictors of BMR, were significant variables in the regression, the statistical difference between the obese and non-obese group remained. These findings therefore confirm the conclusions of some earlier reports, ${ }^{19} 2739$ although not all found a difference between obese and non-obese adolescents. ${ }^{40}$ When fat mass was included in the analysis, the difference between obese and non-obese subjects was lost. However, this does not imply that in obese adolescents fat mass is (more) metabolically active. One explanation is that obesity causes changes in chemical composition of fatfree mass. ${ }^{41}{ }^{42}$ Using theoretical calculations it has been shown that, owing to a relative increase in total body water, the density of fatfree mass is decreased in the obese state, leading to an overestimation of fat mass when measured by underwater weighing. ${ }^{43}$ However, in the present study total body water was measured directly by deuterium dilution, so this variable cannot therefore account for the increased BMR. Another explanation is that the increased BMR adjusted for fat-free mass is not based on an underestimation of fat-free mass but on an increase in the mass of metabolically active organs. Obesity could be associated with a relative increase in internal organ mass compared with muscle mass. As the major organs of the body (the brain, heart, kidney, and liver, including the splanchnic bed) have similar high levels of basal metabolism compared with skeletal muscle, ${ }^{44}$ a higher proportion of these organs in the fat-free mass would be reflected by an increase in BMR, even when the result is adjusted for fat-free mass.

In contrast to the findings of Katch et $a l,{ }^{19}$ our study showed a higher BMR in male subjects, independently of body composition. As for obesity, one could speculate that the relative organ mass in female subjects is smaller than in male subjects or-as has been shown in adults - that $\mathrm{Na} / \mathrm{K}$-ATPase activity is reduced in females. ${ }^{45}$ This latter is also related to a lower $\mathrm{BMR}^{46}$

Recently, existing equations to estimate BMR in non-obese children aged 10-15 years have been thoroughly evaluated. ${ }^{26}$ The investigators concluded that weight was the single most important factor in the equations for either sex, and that the $\mathrm{FAO} / \mathrm{WHO} / \mathrm{UNU}$ equations performed best in predicting BMR in this specific age group. In our present data, however, not all subgroups were well predicted by $\mathrm{FAO} / \mathrm{WHO} / \mathrm{UNU}$ equations. Both WHO-1 and WHO-2 were good predictors of BMR in non-obese female subjects but underestimated 
the BMR in non-obese male subjects, resulting in a general underestimation of energy expenditure in the non-obese group as a whole. The underestimation of energy requirements was anticipated by the FAO expert committee, because their database included subjects who may have been on limited energy intakes before the BMR measurement, as well as Indian subjects who were found to have BMR values that were approximately $10 \%$ below the average. ${ }^{18}$ However, in the present obese group, the BMR in male subjects was overestimated by WHO-1 as well as by WHO-2, resulting in a general overestimation of $\mathrm{BMR}$ by $\mathrm{FAO} / \mathrm{WHO} / \mathrm{UNU}$ equations for obese male subjects. Estimation by WHO-2 seemed similar to the measured BMR; however, this was merely the result of a compensating effect of the underestimated BMR in female subjects.

The overestimation of BMR by WHO standards in 10-16 year old healthy children has been reported before, in both obese and non-obese subjects. ${ }^{24}$ We do not have an explanation for these conflicting findings other than that the measurement of BMR is known to be subject of much error. One may conclude from these data that WHO-1a provides the best BMR prediction for the obese adolescents, while WHO-1 adequately predicts BMR in obese as well as non-obese female subjects, but gives the worst prediction in obese male subjects. Thus a combination of the use of WHO-2 for non-obese adolescents and WHO-1a for obese adolescents results in the best fit along the line of identity (fig 1), although the amount of variation around this line shows - as already the FAO expert committee already concluded - that equations cannot substitute for direct BMR measurements.

The sex effect on ADMR is actually based on BMR differences, as sex only has a negative effect on ADMR when corrected for age and fat-free mass and not when adjusted for BMR. Therefore, in concordance with data on 4-10 year old children, ${ }^{47}$ our present study showed no effect of gender on activity related energy expenditure. Conversely, in a meta-analysis of adult data, ${ }^{48}$ the sex difference was also demonstrated for ADMR when adjusted for $\mathrm{BMR}$, and it was independent of fat mass. This may indicate that the sex effect on activity related energy expenditure does not appear before adulthood.

In contrast to the effect of obesity on BMR, $\mathrm{ADMR}$ is not directly influenced by an excess of fat mass when adjustment is made for fat-free mass. Accordingly, one would expect the energy expenditure of physical activity to be lower in obese individuals, as physical activity and BMR account for about $90 \%$ of ADMR. The ratio of ADMR to BMR (physical activity level) provides a measure of activity related energy expenditure corrected for BMR, assuming that diet induced energy expenditure is a constant proportion of ADMR.${ }^{18}$ In the present study, the physical activity level of male adolescents was within the range of 1.6-1.75, as suggested by $\mathrm{FAO} / \mathrm{WHO} / \mathrm{UNU}$. The average physical activity level of female adolescents was higher than suggested $(1.5-1.65),{ }^{18}$ resulting in an underestimation of the calculated ADMR in this subgroup by $\mathrm{FAO} / \mathrm{WHO} / \mathrm{UNU}$, as was reported earlier. ${ }^{37}$

The obese group had a lower physical activity level, indicating a lower activity level overall - which contrasts with other published reports. These have generally been in agreement that obese and non-obese subjects have similar total energy expenditure levels after adjusting for differences in body composition. ${ }^{48}$ In this context, an alternative way of measuring differences in activity related energy expenditure is by analysis of covariance based on multiple regression. ${ }^{49}$ Using this technique-which is most valuable in adjusting data with non-zero intercepts, such as the present datathe relation of ADMR with BMR in obese and non-obese male and female subjects was compared using BMR as a covariate. This analysis showed that activity related energy expenditure is indeed similar in the two groups. It also demonstrates that in this age group physical activity increases with age. Although the positive effect of age on ADMR - after adjustment for BMR - was marginal, it might in part explain the low physical activity level in the younger NL-O group and the high physical activity level found in 15 year old Swedish adolescents. ${ }^{38}$ On the other hand it is striking that physical activity decreases both in boys ${ }^{50}$ and girls ${ }^{51}$ just before puberty, while in this study we have shown that activity, adjusted for sex and body composition, further increases during adolescence towards adulthood.

As the data in this study were pooled from three different centres, it is important to test the assumption that the protocols for the measurement of ADMR, BMR, and fat-free mass were comparable. In multiple linear regression models with $\mathrm{BMR}$ or ADMR as the dependent variables, and fat-free mass, fat mass, age, and sex as independent variables, the dummy variables for centre localisation were not significant, indicating that there were no differences that could be accounted for by centre when correction was made for body composition, sex, and age. The assumption of comparable protocols is therefore allowed.

Another point of discussion might be the use of a hydration constant of 0.73 for the calculation of fat-free mass. The hydration factor of fat-free mass changes during growth, ranging from $82 \%$ in the newborn to $72 \%$ in adult life. ${ }^{52-54}$ Indeed, in previous studies ${ }^{30}{ }^{31}$ describing young children through to adulthood, hydration factors were used that were based on maturation, ${ }^{55}$ assessed according to Tanner's puberty ratings. ${ }^{56}$ In the present study, however, not all centres collected maturation data. Thus an average adolescent hydration factor was used.

\section{CONCLUSIONS}

An attempt to combine the sparse data on energy metabolism in obese and non-obese adolescents has been made. Our study combined energy expenditure and body composition data from different centres, and suggests that during adolescence BMR is increased in the obese state and in male 
subjects, independently of differences in body composition. The FAO/WHO/UNU equations underestimate BMR in non-obese adolescents and overestimate BMR in obese male adolescents. For the obese subgroup, we recommend the adult $\mathrm{FAO} / \mathrm{WHO} / \mathrm{UNU}$ BMR prediction equations, based on weight. The ADMR of obese adolescents, adjusted for body composition or BMR, is comparable to that of their non-obese peers, indicating that activity related energy expenditure does not differ between obese and non-obese adolescents.

1 Troiano RP, Flegal KM. Overweight children and adolescents: description, epidemiology, and demographics. Pediatrics 1998;101:S497-504.

2 Seidell JC. Obesity in Europe: scaling an epidemic. Int $\mathcal{F}$ Obes 1995;19:S1-4.

3 Prentice AM, Jebb SA. Obesity in Britain: gluttony or sloth? BMF 1995;311:437-9.

4 Reilly JJ, Dorosty AR, Emmett PM. Prevalence of overweight and obesity in British children: cohort study. BMF 1999:319:1039.

5 Hoffmans MDA, Kromhout D, Lezenne Coulander DC. The impact of body mass index of 78,612 18-year old Dutch men on 32 -year mortality from all causes. $f$ Clin Epidemiol 1988;41:749-56.

6 DiPietro L, Mossberg HO, Stunkard AJ. A 40-year history of overweight children in Stockholm: life-time overweight,
morbidity, and mortality. Int $\mathcal{F}$ Obes Relat Metab Disord 1994;18:585-90.

7 Owens S, Gutin B, Ferguson M, et al. Visceral adipose tissue and cardiovascular risk factors in obese children. $\mathcal{F}$ Pediatr 1998;133:41-5.

8 Luepker RV, Jacobs DR, Prineas RJ, et al. Secular trends of blood pressure and body size in a multi-ethnic adolescent population: 1986 to 1996. F Pediatr 1999;134:668-74.

population: 1986 to 1996 . $\mathcal{F}$ Pediatr $1999 ; \mathbf{1 3 4}: 668-74$.
9 Himes JH, Dietz WH. Guidelines for overweight in adolescent preventive services: recommendations from an expert cent preventive services: recommendations from an expert committee. The Expert Committee on Clinical Guidelines for Overweight in Adolescen

10 Daniels SR. Is there an epidemic of cardiovascular disease on the horizon? F Pediatr 1999;134:665-6.

11 Van Mil EGAH, Goris AHC, Westerterp KR. Debate: physical activity and the prevention of childhood obesityEurope versus the United States. Int F Obes 1999;23:S41-4

12 Guo SS, Roche AF, Chumlea WC, et al. The predictive value of childhood body mass index values for overweight at age 35 y. Am F Clin Nutr 1994;59:810-19.

13 Whitaker RC, Wright JA, Pepe MS, et al. Predicting obesity in young adulthood from childhood and parental obesity. $N$ Engl 7 Med 1997:337:869-73.

14 Basdevant A, Boute D, Borys JM. Who should be educated? Education strategies: could children educate their parents. Int f Obes 1999;23:S10-13.

15 Freedman DS, Dietz WH, Srinivasan SR, et al. The relation of overweight to cardiovascular risk factors among children
and adolescents: the Bogalusa Heart Study. Pediatrics and adolescents: the

16 Westerterp KR. Obesity and physical activity. Int 7 Obes 1999;23:59-64

17 Cheek DB, Mellits D, Elliott D. Body water, height, and weight during growth in normal children. Am $\mathcal{F}$ Dis Child 1966;112:312-17

18 World Health Organisation. Energy and protein requirements: report of a joint $\mathrm{FAO} / \mathrm{WHO} / \mathrm{UNU}$ Expert Consultation. Geneva: WHO, 1985.

19 Katch V, Rocchini A, Becque D, et al. Basal metabolism of obese adolescents: age, gender and body composition effects. Int $\mathcal{7}$ Obes 1985;9:69-76.

20 Katch VL, Marks CC, Bexque MD, et al. Basal metabolism of obese adolescents: evidence for energy conservation compared to normal and lean adolescents. Am $\mathcal{F}$ Human Biol 1990;2:543-51.

21 Dietz WH, Bandini LG, Schoeller DA. Estimates of metabolic rate in obese and nonobese adolescents. 7 Pediat metabolic rate in

22 Firouzbakhsh S, Mathis RK, Dorchester WL, et al. Measured resting energy expenditure in children. $\mathcal{F}$ Pediat Gastroenterol Nutr 1993;16:136-42.

23 Molnár D. Estimates of metabolic rate of obese and nonobese adolescents. F Pediatr 1992;120:660-1

24 Molnár D, Jeges S, Erhardt E, et al. Measured and predicted resting metabolic rate in obese and nonobese adolescents. $f$ Pediatr 1995;127:571-7.

25 Molnár D, Schutz Y. Fat oxidation in nonobese and obese adolescents: effect of body composition and pubertal development. F Pediatr 1998;132:98-104.

26 Henry CJK, Dyer S, Ghusain-Choueiri A. New equation to estimate basal metabolic rate in children aged 10-15 years. Eur f Clin Nutr 1999;53:134-42.
27 Bandini LG, Schoeller DA, Dietz WH. Energy expenditure in obese and nonobese adolescents. Pediatr Res 1990;27: 198-203.

28 Barlow SE, Dietz WH. Obesity evaluation and treatment: expert committee recommendations. Pediatrics 1998;102: E29 (available at http://www.pediatrics.org).

29 Gerver WJM, Bruin Rd. Paediatric morphometrics. Utrecht, the Netherlands: Wetenschappelijke uitgevery Bunge, 1996.

30 Van Mil E, Westerterp K, Kester A, et al. Activity related energy expenditure in children and adolescents with energy expenditure in children and adolescent

31 Van Mil EGAH, Westerterp KR, Gerver WJM, et al. Energy expenditure at rest and during sleep in children with Prader-Willi syndrome is explained by body composition. Am F Clin Nutr 2000;71:752-6.

32 Westerterp KR, Wouters L, Marken-Lichtenbelt WDv. The Maastricht protocol for the measurement of body composition and energy expenditure with labeled water. Obes Res 1995;3:49-57.

33 Schoeller DA, Santen Ev, Petterson DW, et al. Total body water measurement in humans with ${ }^{18} \mathrm{O}$ and ${ }^{2} \mathrm{H}$ labeled water. Am $\mathcal{7}$ Clin Nutr 1980;33:2686-93.

34 Weir JBdV. New methods for calculating metabolic rate with special reference to protein metabolism. F Physiol (Lond) 1949;612:511-21.

35 Davies PSW, Livingstone MBE, Prentice AM, et al. Total energy expenditure during childhood and adolescents [abstract]. Proc Nutrition Soc 1991;50:14A.

36 Livingstone MB, Coward WA, Prentice AM, et al. Daily energy expenditure in free-living children: comparison of heart-rate monitoring with the doubly labeled water method. Am f Clin Nutr 1992;56:343-52.

37 Wong WW. Energy expenditure in female adolescents. $7 \mathrm{Am}$ Coll Nutr 1994;13:332-7.

38 Bratteby LE, Sandhagen B, Fan H, et al. Total energy expenditure and physical activity as assessed by the doubly labeled water method in Swedish adolescents in whom energy intake was underestimated by 7 -d diet records. Am f Clin Nutr 1998;67:905-11.

39 Luke A, Schoeller DA. Basal metabolic rate, fat-free mass, and body cell mass during energy restriction. Metabolism 1992;41:450-6.

40 Elliot DL, Goldberg L, Kuehl KS, et al. Metabolic evaluation of obese and nonobese siblings. 7 Pediatr $1989 ; 114: 957-62$.

41 Halliday D, Hesp R, Stalley SF, et al. Resting metabolic rate, weight, surface area and body composition in obese women. Int $\mathcal{F}$ Obes 1979;3:1-6.

42 Lohman TG. Skinfolds and body density and their relation to body fatness: a review. Hum Biol 1981;53:181-225.

43 Deurenberg P, Leenen R, Van der Kooy K, et al. In obese subjects the body fat percentage calculated with Siri's formula is an overestimation. Eur F Clin Nutr 1989;43:56975.

44 Holliday MA. Metabolic rate and organ size during growth from infancy to maturity and during late gestation and early infancy. Pediatrics 1971;47:169-79.

45 Simat BM, Morley JE, From AHL, et al. Variables affecting measurement of human red cell Na+, K+ ATPase activity: technical factors, feeding, aging. Am 7 Clin Nutr 1984;40 $339-45$.

46 Poehlman ET, Toth MJ, Webb GD. Erythrocyte Na-K pump activity contributes to the age- related decline in resting metabolic rate. f Clin Endocrinol Metab 1993;76: 1054-7

47 Goran MI, Carpenter WH, Poehlman ET. Total energy expenditure in 4- to 6-yr-old children. Am $f$ Physiol 1993;264:E706-11.

48 Goran MI, Carpenter WH, McGloin A, et al. Energy expenditure in children of lean and obese parents. Am 7 Physiol 1995;260:E917-24.

49 Goran MI. Variation of total energy expenditure in humans. Obes Res 1995;3:59-66.

50 Brown DC, Kelnar CJH, Wu FCW. Energy metabolism during male puberty. I. Changes in energy expenditure during onset of puberty in boys. Ann Hum Biol 1996;23: 273-9.

51 Goran MI, Gower BA, Nagy TR, et al. Developmental changes in energy expenditure and physical activity in children: evidence for a decline in physical activity in girls before puberty. Pediatrics 1998;101:887-91.

52 Fomon SJ, Haschke F, Ziegler EE, et al. Body composition of reference children from birth to age 10 years. Am 7 Clin Nutr 1982;35:1169-75.

53 Hergenroeder AC, Klish WJ. Body composition in adolescent athletes. Pediatr Clin North Am 1990;37:1057-83.

54 Hewitt MJ, Going SB, Williams DP, et al. Hydration of the fat-free body mass in children and adults: implications of body composition assessment. Am F Physiol 1993;265:E8895

55 Boileau RA, Lohman TG, Slaughter MH, et al. Hydration of the fat-free body in children during maturation. Hum Biol 1984;56:651-66.

56 Tanner JM. Growth at adolescence, 2nd ed. London: Blackwell, 1962. 